ISSN 1045-6333

\title{
HARVARD
}

JOHN M. OLIN CENTER FOR LAW, ECONOMICS, AND BUSINESS

\section{LOBBYING AND INFORMATION IN POLITICS}

John M. de Figueiredo

Discussion Paper No. 369

$06 / 2002$

Harvard Law School

Cambridge, MA 02138

This paper can be downloaded without charge from:

The Harvard John M. Olin Discussion Paper Series: http://www.law.harvard.edu/programs/olin_center/ 


\title{
Lobbying and Information in Politics
}

\author{
John M. de Figueiredo* \\ Massachusetts Institute of Technology \\ Sloan School of Management \\ 50 Memorial Drive \\ Cambridge, MA 02142-1347 \\ jdefig@mit.edu
}

28 May 2002

\begin{abstract}
This paper introduces the special issue on lobbying of "Business and Politics." It explains why the source of real influence in politics is not money or campaign finance contributions. Rather, the paper argues that lobbying and information provision by interest groups to politicians is much more important factor in explaining governmental policy outcomes.
\end{abstract}

*Sloan School of Management, Massachusetts Institute of Technology, National Bureau of Economic Research, and John M. Olin Senior Research Fellow in Law and Economics at Harvard Law School. 


\section{Lobbying and Information in Politics}

John M. de Figueiredo

(C) 2002 John M. de Figueiredo. All Rights Reserved.

The vast majority of papers written about political influence by interest groups focus on the role of money in politics. Business and interest groups' participation in campaign finance, in the form of hard and soft money, has been the subject of hundreds, if not thousands, of theoretical and empirical studies. Moreover, with the recent congressional moves to reform campaign finance laws, campaign finance studies have received a prominent position in public discourse.

There are two striking results about this line of academic work. First, political action committees (PACs) gave $\$ 245$ million to congressional candidates in form of campaign contributions in 1999-2000 election cycle (about \$123 million annually), and corporations, unions, and interest groups gave $\$ 153$ million in "soft money" to political parties during the 1997-1998 election cycle (about $\$ 76$ million annually). ${ }^{1}$ Yet, the Congress controls a $\$ 2$ trillion budget, about $40 \%$ of which is discretionary spending. This raises a potential puzzle: why do interest groups pay so little (\$200 million annually) to try to influence policy? To answer this question, we turn to a second striking result from the academic literature. There is little credible evidence any of these forms of campaign finance have any effect on policy outcomes. Therefore, the literature generally frames PAC contributions as independent of policy outcome. (This, of course, leaves the question open as to why PACs and corporations give money to candidates and parties at all.)

\footnotetext{
${ }^{1}$ I use the 1997-1998 data on soft money to keep out party activity engaged in support of the presidential election of 2000 .
} 
So what does matter? There is an emerging literature that the more influential instrument in affecting policy outcomes is not campaign contributions, but information. Information takes many forms: statistics, facts, arguments, forecasts, threats, commitments, signals or some combination of the aforementioned. If we assume, as most of political economy literature assumes, that the politician's objective function is re-election (or election to a higher office), then the politician seeks information on how her vote on a given issue will affect the outcome of her next election. There may be intermediate forms of information—such as how many jobs a policy position will create, how will my constituents be affected by an yay or nay vote, whether business leaders will support me in the next election—but ultimately, the key piece of information the politician cares about is how her re-election, or more specifically votes, will be affected by the policy position taken by the politician on the current issue.

The manifestation of information transfer between interest groups and policy-makers is lobbying. Lobbying is about investments in information accumulation, organization, and transfer by corporations and interest groups. Lobbying affects all levels of government, from civil servants in administrative agencies, to the highest levels of elected politicians. Recent disclosures requirements imposed by Congress, suggest that reported lobbying expenditures are almost ten times that of all forms of campaign finance (Milyo et al). In 2000, \$1.51 billion was reportedly spent on lobbying by interest groups. ${ }^{2}$

But even this is not a large amount. Although numerous case studies suggest that lobbying and information transfer greatly affects voting behavior in Congress and influences decision-making in administrative agencies, there has been little statistical evidence. A recent study attempting to quantify the return to lobbying estimates that small amounts of lobbying can have enormous monetary returns, when the constituents lobbying are represented by a legislator 
who can deliver policy. ${ }^{3}$ Moreover, this work suggests that on the margin, interest groups are optimizing by setting marginal benefit to marginal cost of lobbying (de Figueiredo and Silverman 2002). These facts together, the high investment made in lobbying and the high return to lobbying, lend credence to the argument that there is an important empirical justification for believing that lobbying can have a large impact on policy outcomes. Moreover, interest groups need not spend much. Once they provide the legislator with the key piece of credible information of the impact of her voting behavior on re-election, all additional information has little marginal value.

The papers and accompanying commentaries in this issue of the journal address lobbying and information in politics. They theoretically and empirically explain how information affects the behavior of legislators, regulators, and interest groups.

In the first paper "Are PAC Contributions and Lobbying Linked: New Evidence from the 1995 Lobby Disclosure Act," Ansolabehere, Snyder, and Tripathi (AST), integrate the campaign finance literature with the lobbying literature, in examining the access hypothesis. The access hypothesis posits that PAC contributions do not affect policy per se, but are used to signal to a legislator the value of information the interest group has on a particular issue. Thus PAC contributions are mechanisms for interest groups to gain access to legislators so that they can engage in a more valuable activity—lobbying. AST begin with an interesting empirical observation: although only one-fifth of groups have both a PAC and a lobbyist, these groups account for $86 \%$ of PAC expenditures and $70 \%$ of reported lobbying expenditures. This is suggestive of the tight linkage between PAC spending and lobbying. The paper explores this relationship further, showing that interest groups that heavily lobby tend to evenly distribute their

\footnotetext{
${ }^{2}$ There is also surely unreported lobbying.
} 
PAC money to legislators across the ideological spectrum, focusing on legislators in positions of power. Interest groups that lobby very little tend to focus their PAC money on close electoral contests. This, in turn, is consistent with the main prediction of the access hypothesis: interest groups for whom lobbying is important will target their money toward individuals in position of power, independent of partisanship. These are the legislators who are most able to deliver policy. Ideological groups, on the other hand, will tend to focus their money on like-minded partisans in close elections.

In his commentary on this paper, Milyo finds one key contribution of AST is to provide a framework for distinguishing between access-oriented PACs and ideological PACs. However, Milyo notes two additional facts. First, PAC contributions are largely irrelevant to policy outcomes, and second, AST show that PAC contributions are highly correlated with lobbying expenditures, ergo, lobbying is independent of policy outcomes. While he is not ready to embrace this conclusion in its entirety, he does note that the AST paper does point to a possible resolution for this problem when they suggest that future research should account for the multiplicity and heterogeneity of modes of political influence across firms and interest groups. A disaggregation of different types of PACs and different types of lobbying, as is done in AST, may allow us to resolve this paradox.

In the second paper, "The Allocation of Resources by Interest Groups: Lobbying, Litigation, and Administrative Regulation," de Figueiredo and de Figueiredo (DD) examine lobbying of administrative agencies by interest groups. The paper is concerned with the role of subsequent litigation and judicial review of administrative agency decision-making, and how that affects the incentive of interest groups to lobby the agency in the first stage. In doing this, DD

\footnotetext{
${ }^{3}$ In fact, the average return to a dollar of lobbying is shown to be $\$ 11-\$ 45$ for universities that are represented by legislators on powerful committees (Appropriations Committees).
} 
incorporate the behavior of interest groups into the more traditional separation of powers models that have been developed in political science. In the formal model, information is modeled as a resource transfer to the regulator, in much the way that information can be thought of as resources. DD initially show that wealthier interest groups are more likely to lobby. More interesting, though, is how judicial behavior can affect lobbying of administrative agencies. Modeling ideological regulators and courts as responsive to resources, they show that as courts become more biased against change, interest group lobbying investments become smaller, and may be eliminated all together. However, as courts become more responsive to resources, the effect it has on lobbying by interest groups is dependent upon the underlying ideology of the court relative to the interest groups and regulator

This link between interest group lobbying and the behavior of courts is the focal point of Johnston's commentary on this paper. He finds the most important contribution of the paper to be that as the degree of conflict over preferred policy outcomes between the court and the regulator increases, incentives to lobby become weaker and weaker. Indeed, lobbying can be eliminated all together in the extreme case. Johnston then describes an alternative model, where firms must commit real resources, and where, under the right sort of statutory regime, judicial review may actually alter an agency's fundamental incentive to regulate (Johnston 2002). He shows in this set-up, as in DD, an "extreme" form of judicial review can completely alter lobbying incentives. Thus, he argues, the result shown in DD is likely very general, and thus deserves closer attention.

In the third paper "Lobbying and Legislative Organization: The Effect of the Vote of Confidence Procedure," Bennedsen and Feldmann (BF) extend the analysis of lobbying to the international arena in examining how the structure of a legislature affects the interest group's 
incentive to lobby. In particular, they examine how the vote of confidence procedure, which is attached to each bill proposed in a parliamentary system, might affect the ability of information to change a legislator's vote. This, in turn, affects the incentive of interest groups to collect and disseminate information to a legislator. BF develop a infinitely repeated game model of legislative bargaining with a finitely long interelection period and explore how parliamentary systems are different from congressional systems. This is akin to having governments serve a finite period of time before they must call an election, in the absence of a vote of confidence. The key detail is that because every vote in a parliamentary system can be a vote of confidence in the current government, legislators in the majority of such a system have less incentive to change their vote in response to information. Thus, interest groups have less incentive to engage in information gathering and dissemination than they would in a congressional system, where a single vote can fail, but a government will continue.

Baron, in his commentary, extends the BF paper to an infinitely-timed interelection model where legislators are assumed to use stationary strategies (to avoid the multiple equilibria inherent in infinite games). This allows the government to be in power for a potentially infinite duration because, absent the vote of confidence, failure of the government is an exogenous, constant probability, reflected in the actors' discount rates. BF show that if the reelection is far enough away, there will be no lobbying at all in a parliamentary system. Baron sets a bound on this no-lobbying equilibrium based on the discount rate in the infinite period model. The two papers have similar results, despite their different interelection assumptions. In BF, as mandatory re-election get closer, there will be an increase in lobbying; in Baron, as there is increasing uncertainty about government survivability (exogenous probability of survival is low), there is increased lobbying. 
In the final paper, "Closure and Capture in Federal Advisory Committees," Karty describes the history of federal advisory committees (primarily to administrative agencies) and the tendencies of these committees to be captured by interest groups. In this paper, Karty explains why advisory committees play an essential role in policy-making, and how they become susceptible to capture. The paper provides statistics on the origin, number, and composition of all federal advisory committees, and shows universities and research institute members are the most heavily represented group on these committees, giving credence to the "expert" advisory nature of these committees. However, after subjecting his data to a variety of econometric tests, Karty argues that patterns of closure are consistent with capture theories.

In all, the papers extend both the theoretical and empirical reach of the lobbying and influence literature. They illustrate how information provision is important across all rulemaking bodies - legislatures, agencies, and courts - and how theories of information transmission in politics are portable across countries with different structures of government. Bringing together rigorous mathematical and statistical analysis, the papers elevate the discourse on lobbying. Readers should find these papers and commentaries useful in extending their thinking about lobbying and information in politics.

\section{REFERENCES}

de Figueiredo, John M. and Brian S. Silverman (2002). "Academic Earmarks and the Returns to Lobbying," Working Paper \#xxxx. Cambridge, Mass.: National Bureau of Economic Research.

Milyo, Jeffrey, David Primo and Timothy Groseclsoe (2000). "Corporate PAC Campaign Contributions in Perspective," Business and Politics 2(1): 75-88.

Johnston, Jason Scott (2002). "A Game Theoretic Analysis of Alternative Institutions for Regulatory Cost-Benefit Analysis." University of Pennsylvania Law Review _ : _-_. 